\title{
From recruitment to senescence: food shapes the age-dependent pattern of breeding performance in a long-lived bird
}

\author{
Daniel Oro, ${ }^{1,3}$ Noelia Hernández, ${ }^{1}$ Lluis Jover,${ }^{2}$ and MeritXell Genovart ${ }^{1}$ \\ ${ }^{1}$ Population Ecology Group, Institut Mediterrani d'Estudis Avançats (IMEDEA), CSIC-UIB, Miquel Marquès 21, \\ Esporles, Mallorca 07190 Spain \\ ${ }^{2}$ Departamento de Salut Pública, Unitat de Bioestadistica, Universitat de Barcelona, Barcelona 08036 Spain
}

\begin{abstract}
We used a long-term data set (26 years) from Audouin's Gull (Larus audouinii), a long-lived seabird, to address the relationship between the age-dependent pattern of reproductive performance and environmental conditions during breeding. Although theoretical models predict that the youngest and oldest breeders (due to inexperience and senescence, respectively) will perform less well than intermediate age classes, few empirical data exist regarding how this expected pattern varies with food availability. To assess the influence of age and food availability (corrected by population size of the main consumers to take into account density dependence) on a number of breeding parameters (laying dates, egg volume, clutch size, and hatching success), we modeled mean and variances of these parameters by incorporating heterogeneity into generalized linear models. All parameters varied with age and to different degrees, depending on food availability. As expected, performance improved with increased food supply, and the observed age pattern was quadratic, with poorer breeding performances occurring in extreme ages. For most parameters (except for laying dates, for which age and food did not interact), the pattern changed with food somewhat unexpectedly; the differences in performance between age classes were higher (i.e., the quadratic pattern was more noticeable) when food was more readily available than when food availability was lower. We suggest that, under poor environmental conditions, only high-quality individuals of the younger and older birds bred and that the differences in breeding performance between age classes were smaller. Although variances for egg volume were constant, variances for laying dates were highest for the youngest breeders and tended to decrease with age, either due to the selection of higher-quality individuals or to a greater frequency of birds skipping breeding with age, especially when food was in low supply. Our results show that mean and variances of breeding parameters changed with age, but that this pattern was different for each parameter and also varied according to food availability. It is likely that, other than food, certain additional factors (e.g., sex, cohort effects, density dependence) also influence changes in breeding performance with age, and this may preclude the finding of a common pattern among traits and among studies on different taxa.
\end{abstract}

Key words: age pattern; Audouin's Gull; breeding performance; Ebro Delta, western Mediterranean; food availability; Larus audouinii; long-lived birds; selection hypothesis; variance analysis.

\section{INTRODUCTION}

It is a well-known phenomenon in nature that the reproductive performance of individuals improves with age (Forslund and Pärt 1995, Coulson et al. 2001, Bowen et al. 2006, Trumbo 2009). Younger breeders often perform badly and have lower reproductive capacity, which is related to their lack of experience in acquiring sufficient quality and quantity of resources, such as food, mates, and territories (Reid et al. 2003, Sanz-Aguilar et al. 2008). This lack of skills in first-time breeders compared to older individuals commonly translates into costs in successive breeding frequency

Manuscript received 21 February 2013; revised 6 June 2013; accepted 26 June 2013; final version received 28 July 2013. Corresponding Editor: G. Nevitt.

33E-mail: d.oro@uib.es or even in future survival (i.e., the survival-reproduction trade-off; see Stearns 2000). In many long-lived animals, a similar pattern of lower breeding performance has been found in the oldest individuals, a phenomenon known as reproductive senescence (e.g., Jones et al. 2008, Aubry et al. 2009, Rebke et al. 2010).

Three nonexclusive hypotheses exist to explain the poorer performance of younger breeders. The first is the constraint hypothesis (Curio 1983), which states that individuals gain experience and skills over the years (e.g., Nol and Smith 1987, Desrochers 1992, De Forest and Gaston 1996). On the other hand, the restraint hypothesis (Curio 1983) suggests that younger breeders that have higher residual reproductive value than older individuals should reduce their reproductive effort to avoid incurring high survival costs (e.g., Ericsson et al. 2001, Velando et al. 2006). Finally, the selection hypothesis advocates the existence of a selection filter, 


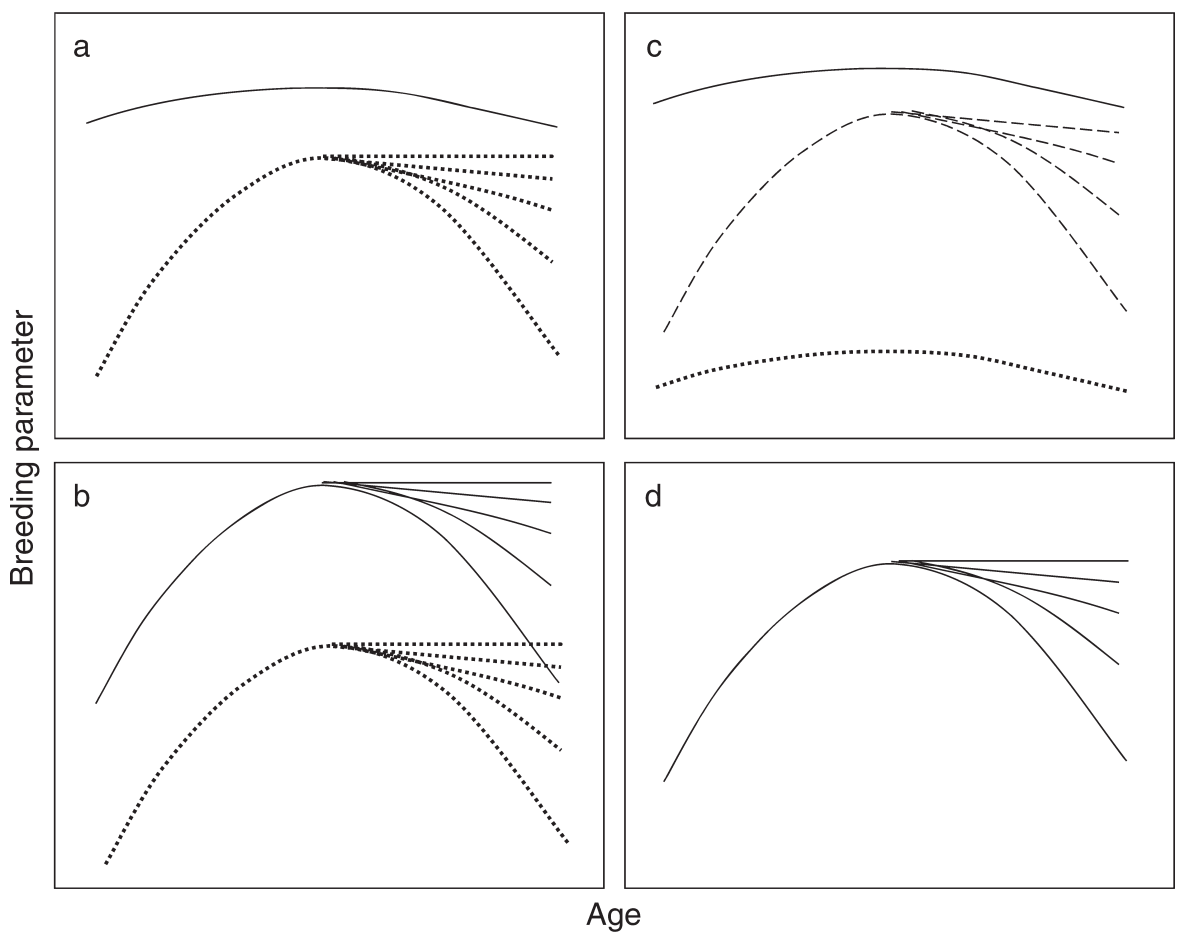

FIG. 1. The four alternative hypotheses built from the published literature (see Appendix: Table A1) to explain the variation in the breeding parameters with age in relation to the environment (see Introduction for explanation): high food availability (solid line), low food availability (dotted line), and intermediate food availability (dashed line, panel c). Panel (a) corresponds to the hypothesis that, under conditions with better food supply, the differences between age classes were less than when food availability was lower. In panel (b), differences between age classes were great but equal under all conditions of food availability; in panel (c), although differences between age classes were small but equal under conditions of higher and lower food availability, a more shaped quadratic pattern was found for intermediate food conditions. Panel (d) fits with the hypothesis that the age effect is independent of food availability. Note that the curves show the mean values for each age class and that the hypothesis with a large variation within classes encompasses different curves, depending on the strength of the senescence phase. For laying dates, the curves should be inverted (i.e., younger and older birds laying later in the season).

operating during the first breeding attempts, that leads to older age classes consisting only of individuals that reproduce well (Cam and Monnat 2000, Reid et al. 2003, Sanz-Aguilar et al. 2008).

Once established that the pattern of reproductive traits varies with age, it still remains to be seen whether this pattern is invariant in natural populations subject to stochastic environments. Life-history theory states that, apart from the intrinsic factors that shape the variation of breeding parameters with age (constrained by tradeoffs), there are also extrinsic factors (i.e., environmental variation) that play an important and interactive role (e.g., Stearns 2000). Thus, it is to be expected that differences in environmental conditions, especially those related to the availability of food during breeding attempts, will cause variations in this pattern (see Fig. 1). Theoretical models (e.g., Stearns 1976) assume that when food is limited there is an increase in reproductive costs, which will be higher for younger breeders under these environmental conditions. Some of the few studies addressing the association between food supply (mostly estimated through proxies such as climate indexes or fisheries data), age, and breeding parameters have found that differences in breeding performance between age classes were highest when food was in short supply (Boekelheide and Ainley 1989, Sydeman et al. 1991, Laaksonen et al. 2002, Bunce et al. 2005); see Fig. 1a. A second, unexpected pattern derived from theoretical expectations (see Fig. 1b) indicates that when food availability is high, breeding parameters are equally high for all age classes (Ratcliffe et al. 1998, Nevoux et al. 2007, Lee 2011). In a study of Great Skuas (Stercorarius skua), breeding success was found to vary with age under intermediate levels of food availability, but was rather constant when food supplies were either high or low (see Fig. 1c) (Ratcliffe et al. 1998). Finally, an additional unexpected pattern suggests that variability is irrespective of food supply (i.e., the only effect is that of age; Fig. 1d) (e.g., Vieyra et al. 2009, Pardo et al. 2013; see Appendix: Table A1 for supporting information).

Here, we used long-term data from a 26-year study to assess how different levels of food availability affect the age-dependent pattern of variability in several breeding parameters of Audouin's Gull Larus audouinii, a longlived colonial bird. Patterns of variability in breeding parameters between age classes are commonly analyzed 
without considering the variance structure of these parameters (e.g., Stearns and Kawecki 1994, Proaktor et al. 2007). However, variance heterogeneity may contain important ecological information and it is thus advisable to incorporate its analysis into the models (Zuur et al. 2009). Thus, we analyzed not only how age and food affected mean values of breeding parameters, but also how variance changed with age and food availability (Nakagawa and Schielzeth 2012, Violle et al. 2012, Pardo et al. 2013). In fact, the few empirical studies that have analyzed the changes in variance of demographic traits found that the greatest variance occurs in older individuals (Gaillard and Yoccoz 2003, Pardo et al. 2013). However, here we go beyond those findings and test how this variance changes not only with age but also with environmental conditions. For instance, we predict that the variance in clutch size of younger breeders will be larger due to heterogeneity in individual quality (i.e., some are able to perform better than others), and will decrease with environmental stress, i.e., lower food availability, because under these circumstances only good younger breeders will in fact breed.

\section{Methods}

The study was carried out in the Audouin's Gull colony at Punta de la Banya (Ebro Delta, western

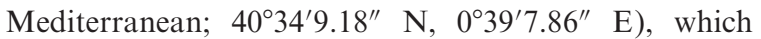
holds $\sim 65 \%$ of the total world population of this gull (e.g., Tavecchia et al. 2007). The site lies on a 2500-ha peninsula of sandy dunes covered by halophilous vegetation, where the gulls build their nests. Audouin's Gulls are iteroparous and clutch size varies between 1 and 4 eggs (mode 3 eggs). Birds start to breed at three years old, and most recruitment in this colony occurs at 3-4 years and decreases sharply thereafter; annual adult survival probability is estimated at 0.91 , and the mean life expectancy is $\sim 14$ years (Oro 1998), calculated as

$$
\sum_{i_{j}}^{i_{k}}=-\frac{1}{\ln \left(\varphi_{i}\right)}
$$

where $\phi$ is survival, $i$ is age, and $j$ and $k$ are pre-adult and adult ages.

The banding program was initiated in 1985 ; by 2010 , 27914 chicks had been banded (annual median 1048, range 86-1792). Since 1988, chicks have also been marked with a plastic band with an individual alphanumeric code that can be read from a distance using a telescope (see Plate 1). For birds marked only with metal bands, incubating adults were detected using a telescope and were trapped at the nest following standard procedures (see Tavecchia et al. 2007). In the period 1994-2011, from the beginning of the laying period onward, nests were identified by searching for banded adults showing reproductive behavior. Once detected, nests were marked and monitored regularly (every 2 or 4 days). During these years, 1631 nests with at least one marked adult were monitored (annual median 101, range 13-143). We recorded the breeding phenology (laying date of the first egg as the number of days elapsed since 12 April (see Fig. 1b), that is, just before the start of laying), clutch size (the number of eggs laid), egg volume (length and maximum width of each egg measured with a digital caliper to $\pm 0.1 \mathrm{~mm}$; see Oro et al. 1996), and hatching success. Only the hatching success of non-abandoned or predated nests was considered. Nests abandoned or predated before the clutch was completed were considered only for laying dates, but not for the rest of parameters; when abandonment and predation occurred once the clutch was completed, these nests were considered also for egg volume and clutch size, but not for hatching success. Parameters related to eggs are an excellent indicator of environmental conditions during the breeding period; for instance, at the population level, egg volume and clutch size increase with improved food availability in the area around the colony (e.g., Oro et al. 1996). The visits (median seven visits for the laying and incubation period lasting $\sim 30$ days) allowed us to control for egg abandonment and predation; thus we were able to obtain unbiased estimates for clutch size. Once the clutch had been started, the laying date of these nests (except if they were predated) was estimated on the basis of the hatching date of the first egg (see Oro et al. 1996). Nests found when hatching was initiated or nests abandoned or predated before we could assess that the clutch was completed (i.e., once after three days - the maximum laying interval in Audouin's Gulls - since the last egg was recorded, except for clutches of four eggs) were not considered, in order to avoid overestimation of true hatching success. Furthermore, nests found once clutches were completed (i.e., consecutive visits did not record more eggs) did not underestimate clutch size or hatching success due to potential previous predation, because nests found on the laying date that suffered predation within the laying interval (i.e., before clutch was potentially completed) were always abandoned (own observations, $N=37$ nests). These filters, together with the fact that $87 \%$ of nests were found on the laying date, made apparent success a reasonable proxy of true hatching success. Because chicks abandon the nest just few days after hatching, breeding success could not be recorded. Given that Audouin's Gulls are groundnesting birds and the large size of the colony (median number of breeding pairs: 11300, range 9170-15329), we only have transversal population data, i.e., most individuals could not be monitored in successive years. From the 1631 nests monitored over the study, 85\% corresponded to individuals monitored only once, and $15 \%$ were monitored twice, the maximum number of replicated data from the same individual. Thus, we considered that pseudoreplication in our data was negligible.

In many cases only one member of the pair was banded, so we checked assortative mating by age by 
using pairs in which both members were marked. The association between the ages of the two members was high $\left(N=152\right.$, Spearman correlation $r_{\mathrm{S}}=0.736, P<$ 0.0001 , mean difference $=1.9$ years, $95 \%$ CI: $1.5-2.3$ years), so we were able to assume that the age of a nonbanded partner was similar to that of the banded (known-age) bird.

The tons ( 1 metric ton $=1 \mathrm{Mg})$ of landings of the trawler fleet in La Rapita, the main fishing port near the colony (Oro and Ruiz 1997), were used as a proxy for annual food availability. In the study area, Audouin's Gulls overlap their foraging areas with the fishing grounds of the trawler fleet (Mañosa et al. 2004, Cama et al. 2012). Gulls exploit discards to a great extent ( $>75 \%$ of their diet; see Oro et al. 1997), and amounts of discards are highly correlated with trawler landings (Oro and Ruiz 1997); as a result, breeding success is correlated with fish landings (Fig. 2). When trawlers do not operate (e.g., during moratoria periods and weekends), gulls feed mainly on small pelagics and less importantly on secondary prey from rice fields $(67 \%$ and $27 \%$ of the gull diet, respectively; Oro et al. 1997). Those landings were corrected for population size (i.e., food per capita, hereafter referred as food) by taking into consideration the number of both Audouin's and Yellow-legged Gulls L. michahellis breeding each year (see methods in Almaraz and Oro 2011) - the latter gull being a sympatric food-competing species - to account for the density dependence of the guild by interference competition recorded in the study colony (Tavecchia et al. 2007, Almaraz and Oro 2011). The availability of discards greatly influences the breeding parameters of the study colony (e.g., Oro et al. 1996; see Fig. 2). The variability in food supply was great and offered a wide range of environmental conditions. For instance, under severe food limitation when discard availability was at its lowest, the modal clutch size decreased to only two eggs, an exceptionally low value for this species (Oro et al. 1996).

We analyzed data using generalized linear models (GLM) to assess the influence of age, food availability per capita (standardized), and their interaction on each breeding parameter. Breeding parameters were modeled as functions of continually valued age and food availability, with model error covariance matrices structured by group-specific error variances for age group and food availability. We used different error and link functions, depending on the distribution of the breeding parameter: Gaussian error and link identity function for average egg volume in a clutch, and laying date, binomial error, and logit link function for clutch size and hatching success. Owing to the fact that clutch size did not follow a Gaussian or a Poisson distribution (range 1-4), that one-egg clutches are rare (10\%), and that most individuals lay three-egg clutches (the modal clutch size, corresponding to $55 \%$ of the clutches monitored), we treated that parameter as a binomial variable (i.e., laying or not laying a three-egg clutch).
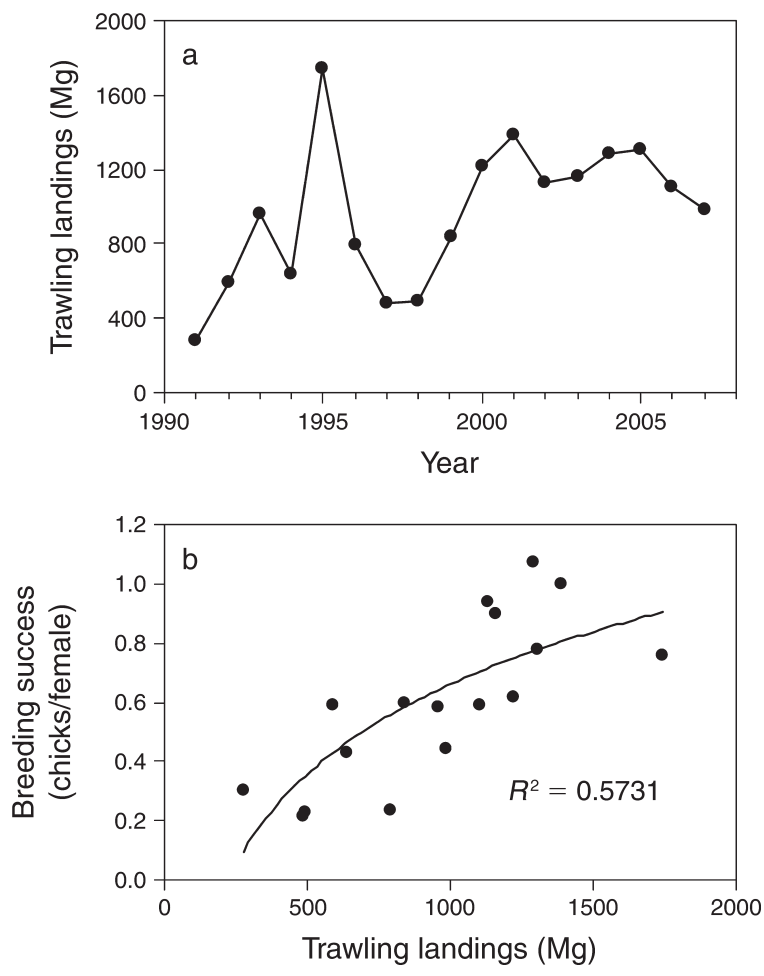

FIG. 2. (a) Variability of trawling landings (as a proxy for discard availability, expressed as metric tons [SI unit $\mathrm{Mg}$ ] of catches from April to June, the whole breeding season) at the main fishing harbor close to the colony of Audouin's Gulls (Larus audouinii) at the Ebro Delta during the period 19912007; and (b) association between breeding success (as mean number of chicks per female) and trawling landings (the value of $R^{2}$ is calculated on a log relationship).

Different models with additive fixed effects and their interactions were analyzed; age was introduced as linear, logarithmic, and quadratic to test for different patterns of age-dependent variation in the breeding parameter (see Fig. 1). Given that egg volume varies with clutch size (Oro et al. 1996), we also introduced clutch size as an explanatory factor for that parameter. We incorporated heterogeneity into the models to test for betweengroup heteroscedasticity, i.e., whether variances vary between age groups and food availability. We obtained the residual variances for each group directly from the GLM. Because hatching success and clutch size were treated as binomial variables, the heteroscedasticity procedure was not feasible because mean and variance are functionally linked. We used biologically meaningful categorizations of ages and food-availability classes; older age classes were pooled to ensure enough statistical power. Ages were categorized into a less constrained distribution (Age A, six classes: 3, 4, 5, 6, 7-14, and $>14$ years old) and two simpler, more constrained structures (Age B, four classes: 3, 4-5, 6-14, and $>14$ years old; Age C, three classes: $3,4-6$, and $>6$ years old) (see Appendix: Table A2). Food availability per capita (as $\mathrm{Mg}$ of fish landed divided by the number of breeding 

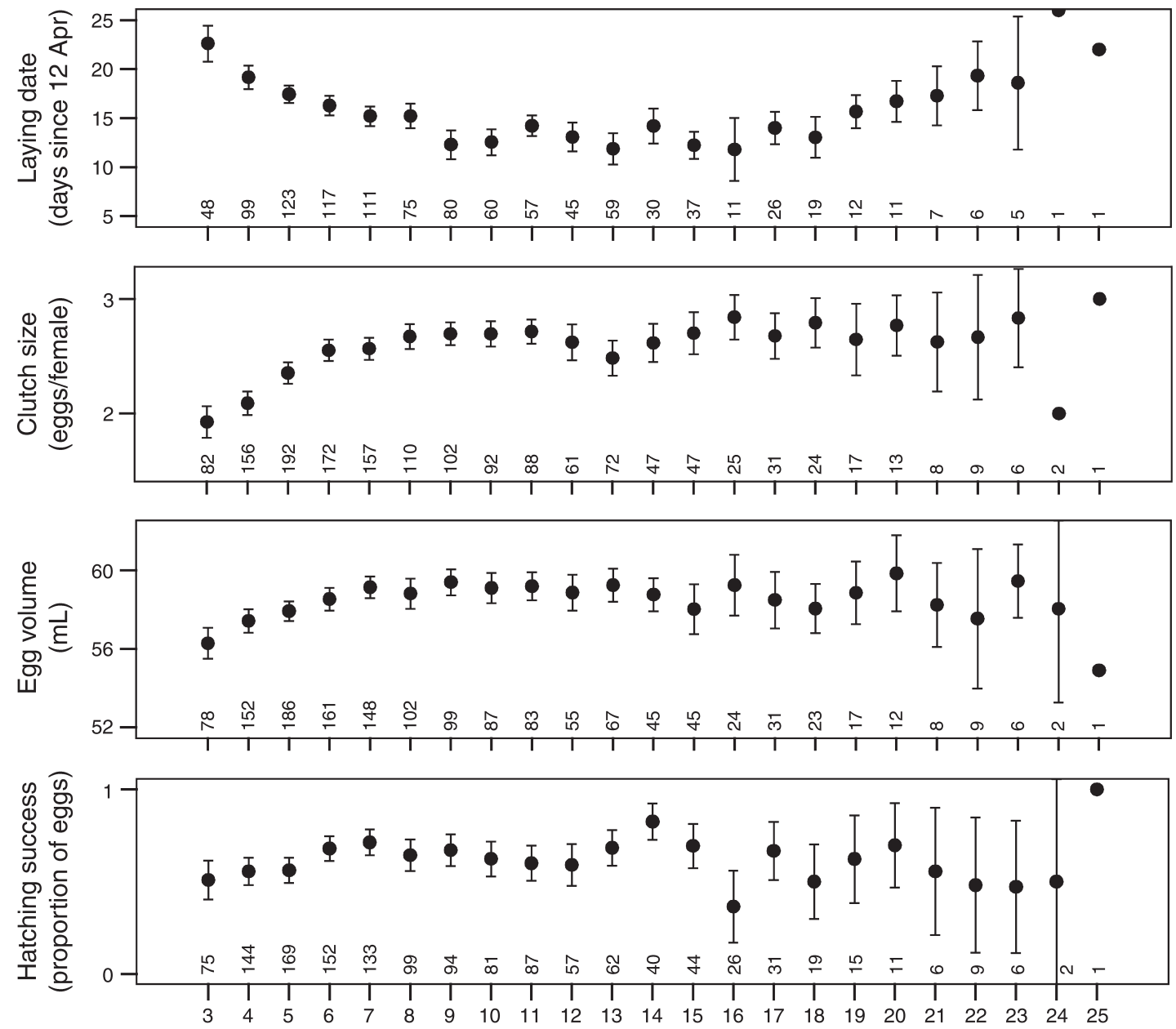

Parent age (yr)

FIG. 3. Relationship between breeding parameters (laying dates, clutch size, egg volume, and hatching success) and age (mean values and 95\% CI) in Audouin's Gulls. Note that the laying date is expressed as days elapsed since 12 April, the date on which females are about to lay their eggs. The numbers above the $x$-axis of each panel are the number of observations for each age class.

pairs of Audouin's and Yellow-legged Gulls) was standardized through a standard normal transformation (by subtracting the mean and dividing the standard deviation) using categories in a single structure with three balanced groups: negative values (seven years with poor food supply per capita), values between 0 and 1 (five good years), and values higher than 1 (six very good years).

The average egg volume in a clutch and mean laying date were fitted with the functions $g l s$ and varIdent from the nlme R package (Pinheiro et al. 2013); 95\% confidence limits of the variances were obtained by utilizing the intervals.gls function from this package; clutch size and hatching success were fitted with the $\mathrm{glm}$ function, in all cases using $\mathrm{R}$ software (http://cran. r-project.org). Model selection was carried out using the AIC (Akaike information criterion) of each model (Burnham and Anderson 2002).

\section{RESUlts}

Breeding ages ranged from three years old (first breeding age) to 25 years old. As usual in these types of data, larger standard errors of older birds are a result of the smaller sample of these ages (Fig. 3). All breeding parameters showed a trend of variation with age, that is, a general improvement in performance during the first attempts, followed by stabilization during intermediate ages (Fig. 3). A senescence pattern also seemed to emerge in all breeding parameters, most obviously for laying dates and less so for clutch size, egg volume, and hatching success (Fig. 3). Model selection showed that food and age played an important role in explaining variation in breeding parameters compared to the null models. Furthermore, these two effects in combination (either with or without interaction) appeared in the best models for all breeding parameters; likewise, age was always present quadratically (see selected models in 


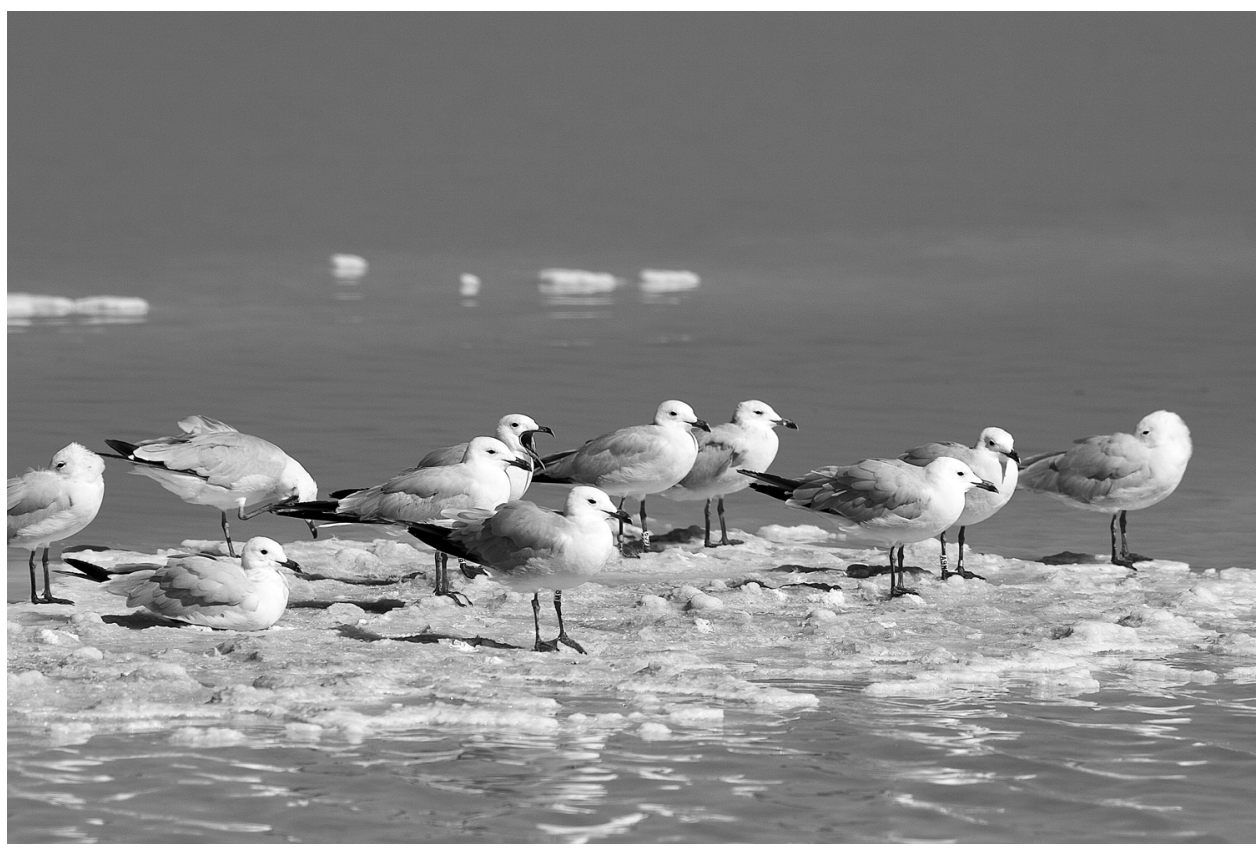

Plate 1. A group of Audouin's Gulls at Punta de la Banya in the western Mediterranean where the study was carried out. Some birds are banded; the second from the right holds the code A9N, and corresponds to a gull banded here as a chick in 1988. Photo credit: Carles Domingo.

Table 1 and Appendix: Table A2). Thus, all breeding parameters significantly increased as food availability improved and a quadratic effect with age appeared (younger and older individuals showing poorer performances; see Fig. 3). When food was in short supply, the pattern of variability in most breeding parameters with age was flatter (i.e., the difference between intermediate ages and both younger and older ages was less) than when food was readily available, an effect that increased the quadratic shape of the association (see Figs. 4 and $5)$. The exception was in laying dates when the selected model included food and age additively (i.e., without their interaction; see Table 1), which gave parallel quadratic curves and similar quadratic patterns, although all ages performed better when food was in good supply (Fig. 5).

\section{Effects of food supply on the variance of the age pattern}

In tests for heteroscedasticity, the variances behaved differently for each breeding parameter, changing with age (four age classes) and food availability for laying dates, but remaining constant for egg volume (homogeneous variances for all ages and food classes); see Appendix: Table A2. For laying dates, the greatest variances occurred in 3-year and 4-5 year-old birds when food was in good supply, i.e., when individuals of different quality found suitable conditions to start breeding; the lowest variance occurred in the oldest birds ( $>14$ years old) when food availability was highest (Fig. 6).

\section{Discussion}

\section{Age variation pattern}

Our results show clear evidence of quadratic variation of age in several breeding parameters: younger and older birds laid later in the season (an indication of poorer acquisition of resources for reproduction), laid fewer eggs per clutch, laid smaller eggs, and hatched fewer eggs at the end of incubation. All studies dealing with multiple life-history and physiological traits report differences in the degree to which age influences each trait, ranging from no effect to a strong association, either linear or quadratic (e.g., Weimerskirch 1990, Blas et al. 2009, Lecomte et al. 2010, Pardo et al. 2013). Nevertheless, no common pattern in differences between and within traits across taxa has yet emerged, probably because additional factors other than age (e.g., sex, individual quality, experience, mate and site fidelity, cohort effects, age of the mate, density dependence, and stochastic fluctuations of food; see, for instance, Coulson et al. 2001) potentially influence the multi-trait pattern.

Even though an increase in breeding performance with age and experience has been widely reported in many iteroparous organisms (e.g., Berkeley et al. 2004, Bowen et al. 2006, Weladji et al. 2006, Trumbo 2009), the final decline in performance in older individuals has seldom been assessed (Monaghan et al. 2008) and has been recorded only in some but not all studied taxa (e.g., Vieyra et al. 2009, Rebke et al. 2010, Orzack et al. 2011, Pardo et al. 2013). In younger birds, poorer breeding 
TABLE 1. Modeling the effects of age (mean and variance simultaneously) of Audouin's Gulls (Larus audouinii) on breeding parameters.

\begin{tabular}{|c|c|c|c|c|}
\hline Model, by breeding parameter & Log likelihood & $K$ & AIC & $\Delta \mathrm{AIC}$ \\
\hline \multicolumn{5}{|l|}{ Laying dates $\dagger$} \\
\hline 1) Null & -3297.29 & 13 & 6620.57 & 365.99 \\
\hline 2) Food & -3211.69 & 14 & 6449.37 & 194.79 \\
\hline 3) Age & -3264.42 & 14 & 6556.85 & 302.27 \\
\hline 4) Food + Age & -3161.98 & 15 & 6353.95 & 99.37 \\
\hline 5) Food $\times$ Age & -3111.16 & 17 & 6256.31 & 1.73 \\
\hline 6) $\log ($ Age $)$ & -3236.10 & 14 & 6500.20 & 245.62 \\
\hline 7) Food + log(Age $)$ & -3138.57 & 15 & 6307.15 & 52.57 \\
\hline 8) Food $\times \log ($ Age $)$ & -3134.19 & 16 & 6300.39 & 45.81 \\
\hline 9) $\mathrm{Age}^{2}$ & -3183.10 & 15 & 6396.19 & 141.61 \\
\hline 10) Food + Age $^{2}$ & -3111.29 & 16 & 6254.58 & o \\
\hline 11) Food $\times \mathrm{Age}^{2}$ & -3110.95 & 18 & 6257.90 & 3.32 \\
\hline \multicolumn{5}{|l|}{ Clutch size } \\
\hline 1) Null & -1858.78 & 1 & 3720.06 & 24.11 \\
\hline 2) Food & -1850.56 & 2 & 3705.12 & 9.17 \\
\hline 3) Age & -1858.86 & 2 & 3721.73 & 25.78 \\
\hline 4) Food + Age & -1850.55 & 3 & 3707.12 & 11.17 \\
\hline 5) Food $\times$ Age & -1850.47 & 4 & 3708.96 & 13.01 \\
\hline 6) $\log ($ Age $)$ & -1858.78 & 2 & 3721.56 & 25.61 \\
\hline 7) Food + $\log ($ Age $)$ & -1850.02 & 3 & 3708.07 & 10.23 \\
\hline 8) Food $\times \log ($ Age $)$ & -1850.02 & 4 & 3708.07 & 12.12 \\
\hline 9) $\mathrm{Age}^{2}$ & -1851.54 & 3 & 3709.10 & 13.15 \\
\hline 10) Food $+\mathrm{Age}^{2}$ & -1845.79 & 4 & 3699.60 & 3.65 \\
\hline 11) Food $\times$ Age $^{2}$ & -1841.94 & 6 & 3695.95 & 0.00 \\
\hline \multicolumn{5}{|l|}{ Egg volume } \\
\hline 1) Null & -3896.14 & 2 & 7796.28 & 87.42 \\
\hline 2) Food & -3879.60 & 3 & 7765.21 & 56.35 \\
\hline 3) Age & -3887.65 & 3 & 7781.29 & 72.43 \\
\hline 4) Clutch size & -3875.57 & 4 & 7759.13 & 50.27 \\
\hline 5) Food + Clutch size + Age & -3855.42 & 6 & 7722.84 & 13.99 \\
\hline 6) Food + Clutch size & -3861.57 & 5 & 7733.14 & 24.28 \\
\hline 7) Age + Clutch size & -3872.43 & 5 & 7754.86 & 46.00 \\
\hline 8) Food + Age & -3866.80 & 4 & 7741.60 & 32.74 \\
\hline 9) $\log$ (Age) & -3879.51 & 3 & 7765.01 & 56.15 \\
\hline 10) $\mathrm{Age}^{2}$ & -3871.04 & 4 & 7750.08 & 41.22 \\
\hline 11) $\mathrm{Age}^{2}+$ Clutch size & -3861.43 & 6 & 7734.86 & 26.00 \\
\hline 12) Clutch size $\times \mathrm{Age}^{2}$ & -3860.34 & 10 & 7740.67 & 31.81 \\
\hline 13) Food $\times$ Age $^{2}$ & -3852.38 & 7 & 7718.75 & 9.89 \\
\hline 14) Clutch size + Food $+\mathrm{Age}^{2}$ & -3847.63 & 7 & 7709.27 & 0.41 \\
\hline 15) Food + Clutch size $\times$ Age $^{2}$ & -3846.63 & 11 & 7715.26 & 6.40 \\
\hline 16) Clutch size + Food $\times$ Age $^{2}$ & -3845.43 & 9 & 7708.86 & 0.00 \\
\hline \multicolumn{5}{|l|}{ Hatching success } \\
\hline 1) Null & -1859.03 & 1 & 3720.06 & 24.17 \\
\hline 2) Food & -1850.56 & 2 & 3705.12 & 9.23 \\
\hline 3) Age & -1858.86 & 2 & 3721.72 & 25.83 \\
\hline 4) Food + Age & -1850.55 & 3 & 3707.10 & 11.21 \\
\hline 5) Food $\times$ Age & -1850.47 & 4 & 3708.93 & 13.05 \\
\hline 6) $\log ($ Age $)$ & -1858.78 & 2 & 3721.55 & 25.67 \\
\hline 7) Food + $\log ($ Age $)$ & -1850.08 & 3 & 3706.16 & 10.28 \\
\hline 8) Food $\times \log ($ Age $)$ & -1850.02 & 4 & 3708.04 & 12.16 \\
\hline 9) $\mathrm{Age}^{2}$ & -1851.54 & 3 & 3709.08 & 13.19 \\
\hline 10) Food + Age ${ }^{2}$ & -1845.79 & 4 & 3699.57 & 3.68 \\
\hline 11) Food $\times$ Age $^{2}$ & -1841.94 & 6 & 3695.89 & $\mathbf{0}$ \\
\hline
\end{tabular}

Notes: The best structure of variances (see Appendix: Table A2) was used for each parameter: for laying dates, food in interaction with age B structure; for clutch size, food in interaction with age $\mathrm{C}$ structure; and homoscedasticity for egg volume. Once the best variance structure was selected, we kept that structure for all models. Modeling followed a strategy of stepwise forward addition of parameters. We started with the null model with no effects, then single effects were tested, and finally interactions between these effects. Terms are: $K$, the number of identifiable parameters; AIC, Akaike's information criterion; $\triangle \mathrm{AIC}$, the difference in AIC value of the model with respect to the AIC value of the best model. The final selected model is in bold. Interaction between factors is denoted by " $X$ " and "+" indicates an additive effect between factors. $\mathrm{Age}^{2}$ indicates a quadratic effect of age on the breeding parameter. Food is the availability of food per capita (see Methods).

$\uparrow$ Twelve of the parameters $(K)$ in all models corresponded to the variance structure (four age classes $\times$ three food classes).

¥ One of the parameters $(K)$ in all models corresponded to a single variance value. 

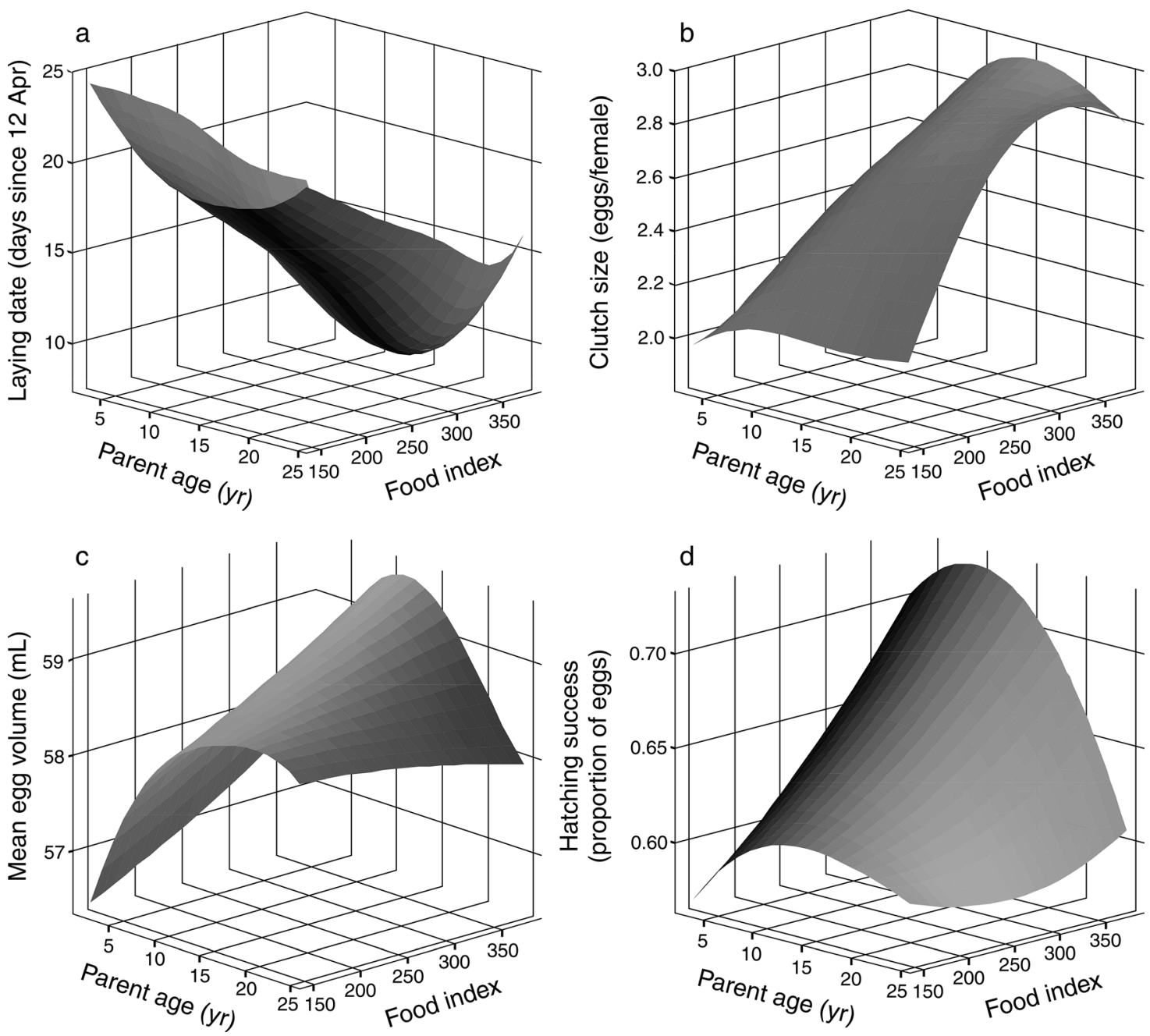

FIG. 4. Smoothing regression surfaces of the raw data, depicting the effects of age (ranging from 3 to 25 years of age) across all observed values of food availability (expressed as a food index of trawling discards per capita) on (a) laying dates, (b) clutch size, (c) average egg volume in three-egg clutches, and (d) hatching success of Audouin's Gulls in the Ebro Delta. The food index is a measure of density dependence because it reflects not the absolute amount of food available, but how much food is available for each individual (total trawling discards divided by the number of gulls).

performance is likely to indicate a lack of experience, especially when interference competition for resources with older (i.e., more experienced) birds occurs. Navarro et al. (2010) found that in Audouin's Gulls, younger breeders consumed lower quality prey in rice fields with lower energetic content, probably to avoid competition with the older birds that mainly consume lipid-rich fish. The decline in breeding performance observed in old gulls is the result of senescence, probably due to a deterioration of their functional abilities, particularly a lower foraging efficiency (e.g., Catry et al. 2006, Lecomte et al. 2010). This lower foraging efficiency in older birds would be more marked when food availability per capita decreased (i.e., when intra- and interspecific competition increased), determining a lower reproductive performance under such conditions. Although actuarial senescence (i.e., of survival) is a widespread phenomenon, reproductive senescence has been less studied and seems to be less common because it may also depend on food availability, on traits such as body size and migratory behavior, or on trade-offs between early- and late-life reproduction (Reed et al. 2008, Aubry et al. 2009, Berman et al. 2009).

\section{Influence of food supply per capita on pattern in age variation}

Once we had demonstrated the quadratic effect of age on all breeding parameters analyzed, the major challenge of our study was to assess whether and how this common pattern in nature varies with food availability, the main environmental driver of breeding performance (in the absence of predation). As expected, performance improved with increased food supply in all parameters. In terms of laying dates, performance varied quadrat- 

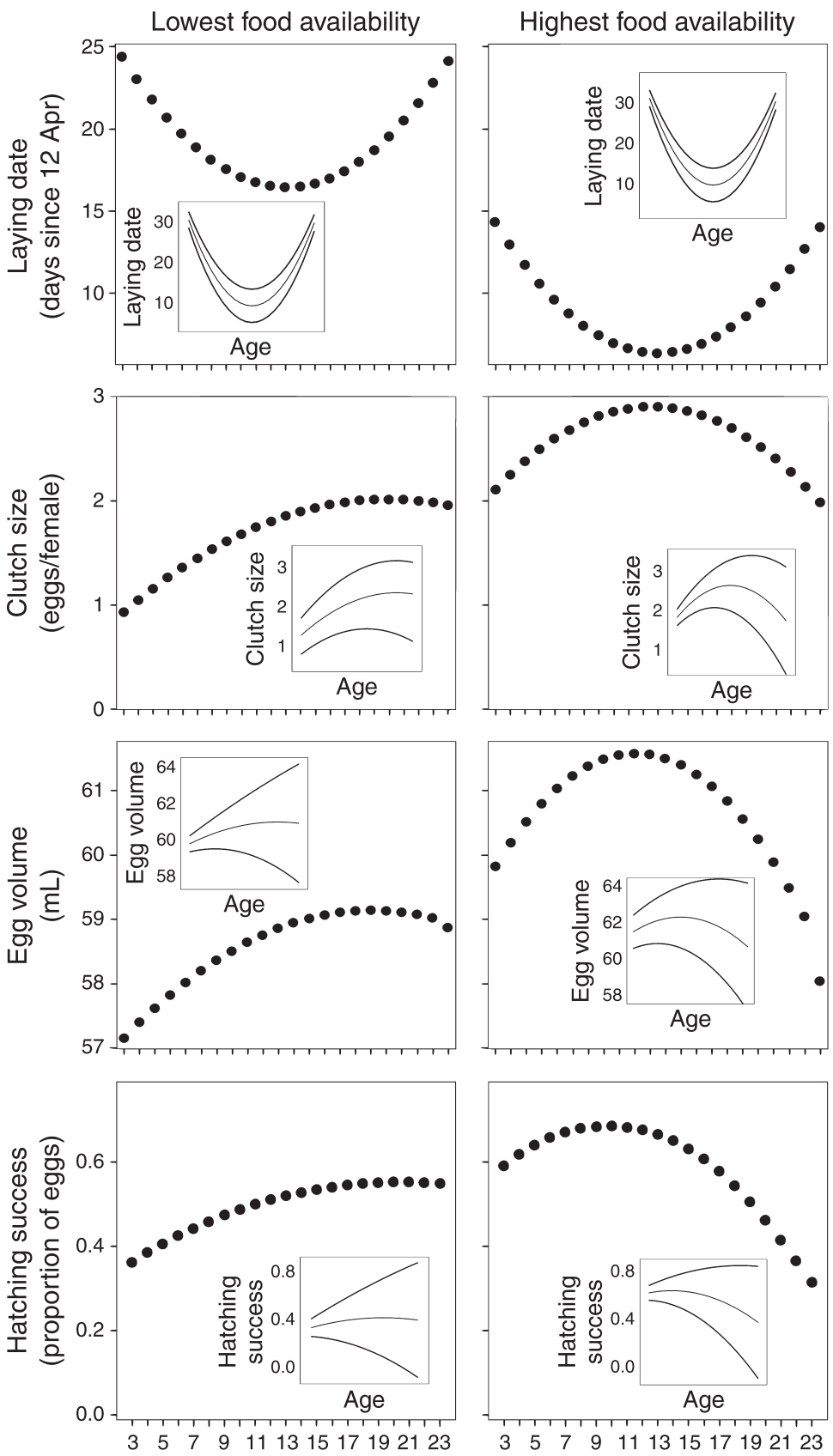

Parent age (yr)

FIG. 5. Variation in the breeding parameters with age for the two extreme values of food availability per capita (years with lowest and highest values) to explore the two patterns of age variation under different food conditions. Solid circles show predicted mean values for each age estimated from the best model (see Table 1 and Appendix: Table A2). Inset figures show the mean values together with their $95 \%$ CI (same parameters as the respective axes in the main panels).

ically with age and increased in parallel with food availability per capita: birds laying earlier were in better condition, and this was the only parameter in Audouin's Gulls that behaved like this (i.e., food did not alter the age pattern). Egg laying occurs at the beginning of the reproductive season and should be the breeding parameter less affected by environmental noise, which should accumulate across the season. This probably causes an increase in the effects of different conditions of food availability per capita for each age class, although the difference with other parameters and with laying dates in closely related organisms, e.g., Western Gulls $L$. occidentalis (Sydeman et al. 1991; see Appendix: Table A1), remain poorly understood. For the rest of the 
reproductive parameters (clutch size, egg volume, and hatching success), the age pattern of breeding performance varied markedly with different levels of food availability and in an unexpected way. When food per capita was in short supply, the resulting quadratic age pattern was less marked (Fig. 5), even though most studies have found that differences in breeding performance between age classes decrease with improving feeding opportunities (see Appendix: Table A1). For instance, Ezard et al. (2006) report that young Common Terns (Sterna hirundo) performed well only in highquality years, as is the case in Brandt's Cormorants (Phalacrocorax penicillatus) (Boekelheide and Ainley 1989). By contrast, our results show that the quadratic age pattern in Audouin's Gull for all parameters is more apparent under good conditions (except for laying dates; see Fig. 5), when middle-aged individuals greatly improve their breeding performance, thereby increasing differences in reproductive performance vis-à-vis older birds.

Variances in laying dates decreased with age and under all conditions; higher variance differences within age classes in breeding performance were found in younger birds. These results suggest that heterogeneity in individual quality exists within young age classes. Heterogeneity within age classes has been invoked by many previous studies (e.g., Sydeman et al. 1991, Cam and Monnat 2000, Barbraud and Weimerskirch 2005, McCleery et al. 2008, Lescroël et al. 2009, Oro et al. 2010, Péron et al. 2010, Desprez et al. 2011) and is the basis for the selection hypothesis (e.g., Nevoux et al. 2007; but see Rebke et al. 2010). This hypothesis is also supported by the low variances in older age classes (Fig. 6), which suggest that heterogeneity in individual quality for these birds was low. The average individual quality should increase with age, once young breeders of lower quality are removed from the population due to the costs of reproduction (e.g., Sanz-Aguilar et al. 2008). Additionally, it remains to be understood whether skip breeding, a practice commonly recorded in many seabird species including other gulls (e.g., Cam and Monnat 2000, Pyle et al. 2001, Sanz-Aguilar et al. 2008, Goutte et al. 2011), also plays a role in the low variances recorded in older Audouin's Gulls.

To our knowledge, only Pardo et al. (2013) have ever analyzed how the variances of several demographic traits change with age; these authors found a U-shaped pattern in the Black-browed Albatrosses (Thalassarche melanophrys), with middle-aged individuals having the lowest variances. Thus, the patterns present in these two species coincide in the high variances for younger birds and the lower variances for middle-aged birds, whereas the least variance in Audouin's Gulls occurs in older individuals. The difference in the two species-specific patterns appears in older age classes, because variances in old Black-browed Albatrosses were high (and similar to variances of younger birds), whereas those in old Audouin's Gulls were the lowest. This is likely to be

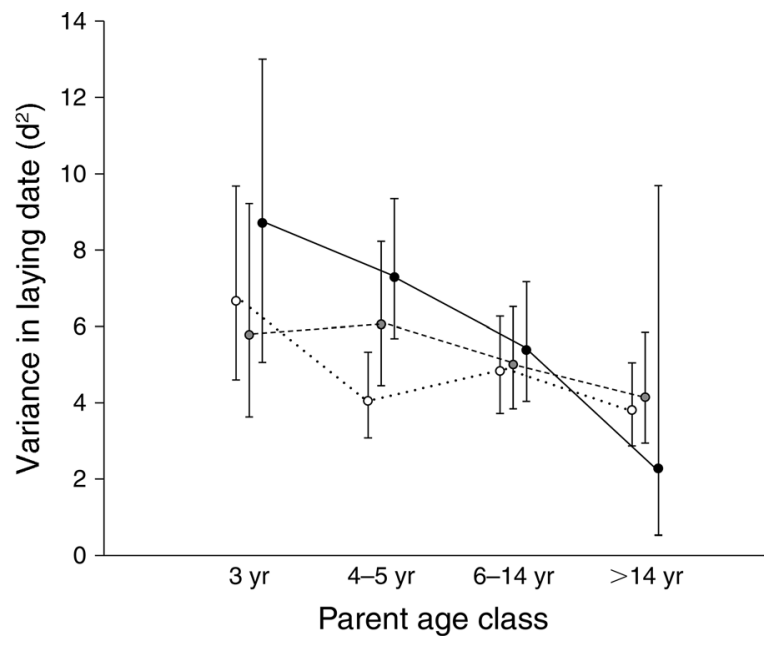

FIG. 6. Variances for each categorized age class (together with their 95\% CI; see Methods) in laying dates of Audouin's Gulls in the Ebro Delta. Variance also varied with different categories of food availability: low (dotted line), intermediate (dashed line), and high (solid line).

explained by the differences in life-history strategies between the two species: albatrosses are extremely longlived birds, lay a single egg, and have sabbatical (nonbreeding) years, whereas Audouin's Gulls have a lower survival, lay $2-3$ eggs, and are thus bet-hedgers, i.e., species that reduce the temporal variance in fitness at the expense of lowered arithmetic mean fitness. Our results suggest that a selection process takes place as the individual grows older, resulting in, at least for some parameters such as laying dates, progressively lower heterogeneity in quality and breeding performance. In other words, the average laying dates of younger and older Audouin's Gulls were later, and while variance in younger birds was high (suggesting a large degree of individual heterogeneity with some breeders performing well and others doing badly), variance in older and experienced breeders was low (suggesting that most old and experienced gulls performed similarly). Despite not analyzing how variances changed with age and environmental conditions, other studies have reported a similar pattern, i.e., an effect of selection on the best performing individuals and thus a progressive homogenization of performance with age (Daunt et al. 1999, Cam and Monnat 2000, Barbraud and Weimerskirch 2005, Nevoux et al. 2007).

\section{CONCLUSION}

Together with other factors such as sex, behavioral processes, and the varying costs of early reproduction, our results demonstrate that age and environmental conditions (in the form of food availability per capita) interact to shape differing aging patterns in an array of breeding parameters under natural conditions. These patterns vary from soft quadratic shapes in harsh environments (little effect of inexperience and senes- 
cence due to individual heterogeneity in quality and selection) to strongly quadratic patterns (important effect of inexperience and senescence) during good years when middle-aged individuals greatly improve their breeding performance. These two contrasting patterns, which are determined by food availability per capita (i.e., considering density dependence and thus competition; see Coulson et al. 2001), are rather unexpected because none of the studies analyzing the interaction between age and food conditions found that differences in breeding performance between age classes were lower when food was in shorter supply (see Fig. 1). The inclusion of the heterogeneity of variance in our analysis allowed us to shed some light on that particular pattern of the influence of food conditions and competition in the age pattern of breeding performance found in Audouin's Gulls. Variance variability between age classes suggests that important ecological processes, for example, the fact that selection decreases as individuals become older and their average quality increases, affects the patterns of age variation in breeding performance.

\section{ACKNOWLEDGMENTS}

We are indebted to all the people participating in the Audouin's Gull monitoring at the Ebro Delta over the years, particularly to Albert Bertolero and Julia Piccardo. Staff of the PN Delta de l'Ebre also offered logistic support. Simone Tenan and Isabel Palomera kindly helped with statistics and fishing landing data, respectively. Three anonymous reviewers and Gabrielle Nevitt provided helpful and constructive comments on previous drafts. Mike Lookwood and Hannah Williams corrected the English. Funds were provided by several agencies such as Generalitat de Catalunya, the Spanish Ministry of Science (grant ref. CGL2009-08298), and the Regional Government of Balearic Islands (EU FEDER funds).

\section{Literature Cited}

Almaraz, P., and D. Oro. 2011. Size-mediated non-trophic interactions and stochastic predation drive assembly and dynamics in a seabird community. Ecology 92:1948-1958.

Aubry, L. M., D. N. Koons, J. Y. Monnat, and E. Cam. 2009. Consequences of recruitment decisions and heterogeneity on age-specific breeding success in a long-lived seabird. Ecology 90:2491-2502.

Barbraud, C., and H. Weimerskirch. 2005. Environmental conditions and breeding experience affect costs of reproduction in Blue Petrels. Ecology 86:682-692.

Berkeley, S. A., C. Chapman, and S. M. Sogard. 2004. Maternal age as a determinant of larval growth and survival in a marine fish, Sebastes melanops. Ecology 85:1258-1264.

Berman, M., J. M. Gaillard, and H. Weimerskirch. 2009. Contrasted patterns of age-specific reproduction in long-lived seabirds. Proceedings of the Royal Society B 276:375-382.

Blas, J., F. Sergio, and F. Hiraldo. 2009. Age-related improvement in reproductive performance in a long-lived raptor: a cross-sectional and longitudinal study. Ecography 32:647-657.

Boekelheide, R. J., and D. G. Ainley. 1989. Age, resource availability, and breeding effort in Brandt's Cormorant. Auk 106:389-401.

Bowen, W. D., S. J. Iverson, J. I. McMillan, and D. J. Boness. 2006. Reproductive performance in grey seals: age-related improvement and senescence in a capital breeder. Journal of Animal Ecology 75:1340-1351.
Bunce, A., S. J. Ward, and F. I. Norman. 2005. Are age-related variations in breeding performance greatest when food availability is limited? Journal of Zoology 266:163-169.

Burnham, K. P., and D. R. Anderson. 2002. Model selection and multimodel inference: a practical information-theoretic approach. Springer-Verlag, New York, New York, USA.

Cam, E., and J. Y. Monnat. 2000. Apparent inferiority of firsttime breeders in the kittiwake: the role of heterogeneity among age classes. Journal of Animal Ecology 69:380-394.

Cama, A., R. Abellana, I. Christel, X. Ferrer, and D. R. Vieites. 2012. Living on predictability: modelling the density distribution of efficient foraging seabirds. Ecography 35:912-921.

Catry, P., R. A. Phillips, J. Forcada, and J. P. Croxall. 2006. Factors affecting the solution of a parental dilemma in albatrosses: at what age should chicks be left unattended? Animal Behaviour 72:383-391.

Coulson, T., E. A. Catchpole, S. D. Albon, B. J. T. Morgan, J. M. Pemberton, T. H. Clutton-Brock, M. J. Crawley, and B. T. Grenfell. 2001. Age, sex, density, winter weather, and population crashes in Soay sheep. Science 292:1528-1531.

Curio, E. 1983. Why do young birds reproduce less well? Ibis 125:400-404.

Daunt, F., S. Wanless, M. P. Harris, and P. Monaghan. 1999. Experimental evidence that age-specific reproductive success is independent of environmental effects. Proceedings of the Royal Society of London B 266:1489-1493.

De Forest, L. N., and A. J. Gaston. 1996. The effect of age on timing of breeding and reproductive success in the ThickBilled Murre. Ecology 77:1501-1511.

Desprez, M., R. Pradel, E. Cam, J. Y. Monnat, and O. Gimenez. 2011. Now you see him, now you don't: experience, not age, is related to reproduction in kittiwakes. Proceedings of the Royal Society B 278:3060-3066.

Desrochers, A. 1992. Age and foraging success in European blackbirds: variation between and with individuals. Animal Behaviour 43:885-894.

Ericsson, G., K. Wallin, J. P. Ball, and M. Broberg. 2001. Agerelated reproductive effort and senescence in free-ranging moose, Alces. Ecology 82:1613-1620.

Ezard, T. H. G., P. H. Becker, and T. Coulson. 2006. The contributions of age and sex to variation in common tern population growth rate. Journal of Animal Ecology 75:1379-1386.

Forslund, P., and T. Pärt. 1995. Age and reproduction in birds - hypotheses and tests. Trends in Ecology and Evolution 10:374-378.

Gaillard, J.-M., and N. G. Yoccoz. 2003. Temporal variation in survival of mammals: a case of environmental canalization? Ecology 84:3294-3306.

Goutte, A., M. Kriloff, H. Weimerskirch, and O. Chastel. 2011. Why do some adult birds skip breeding? A hormonal investigation in a long-lived bird. Biology Letters 7:790-792.

Jones, O. R., et al. 2008. Senescence rates are determined by ranking on the fast-slow life-history continuum. Ecology Letters 11:664-673.

Laaksonen, T., E. Korpimäki, and H. Hakkarainen. 2002. Interactive effects of parental age and environmental variation on the breeding performance of Tengmalm's owls. Journal of Animal Ecology 71:23-31.

Lecomte, V. J., et al. 2010. Patterns of aging in the long-lived wandering albatross. Proceedings of the National Academy of Sciences USA 107:6370-6375.

Lee, D. E. 2011. Effects of environmental variability and breeding experience on northern elephant seal demography. Journal of Mammalogy 92:517-526.

Lescroël, A., K. M. Dugger, G. Ballard, and D. G. Ainley. 2009. Effects of individual quality, reproductive success and environmental variability on survival of a long-lived seabird. Journal of Animal Ecology 78:798-806.

Mañosa, S., D. Oro, and X. Ruiz. 2004. Activity patterns and foraging behaviour of Audouin's gulls at the Ebro Delta, NW Mediterranean. Scientia Marina 68:605-614. 
McCleery, R. H., C. M. Perrins, B. C. Sheldon, and A. Charmantier. 2008. Age-specific reproduction in a long-lived species: the combined effects of senescence and individual quality. Proceedings of the Royal Society B 275:963-970.

Monaghan, P., A. Charmantier, D. H. Nussey, and R. E. Ricklefs. 2008. The evolutionary ecology of senescence. Functional Ecology 22:371-378.

Nakagawa, S., and H. Schielzeth. 2012. The mean strikes back: mean-variance relationships and heteroscedasticity. Trends in Ecology and Evolution 27:474-475.

Navarro, J., D. Oro, A. Bertolero, M. Genovart, A. Delgado, and M. G. Forero. 2010. Age and sexual differences in the exploitation of two anthropogenic trophic resources for an opportunistic seabird. Marine Biology 157:2453-2459.

Nevoux, M., H. Weimerskirch, and C. Barbraud. 2007. Environmental variation and experience-related differences in the demography of the long-lived black-browed albatross. Journal of Animal Ecology 76:159-167.

Nol, E., and J. N. M. Smith. 1987. Effects of age and breeding experience on seasonal reproductive success in the song sparrow. Journal of Animal Ecology 56:301-313.

Oro, D. 1998. Audouin's gull account. Pages 47-61 in M. A. Ogilvie, editor. The birds of Western Palearctic. Oxford University Press, Oxford, UK.

Oro, D., L. Jover, and X. Ruiz. 1996. Influence of trawling activity on the breeding ecology of a threatened seabird, Audouin's Gull Larus audouinii. Marine Ecology Progress Series 139:19-29.

Oro, D., and X. Ruiz. 1997. Seabirds and trawler fisheries in the northwestern Mediterranean: differences between the Ebro Delta and the Balearic Is. areas. ICES Journal of Marine Sciences 54:695-707.

Oro, D., X. Ruiz, L. Jover, V. Pedrocchi, and J. González-Solís. 1997. Audouin's Gull diet and adult time budget responses on changes in food availability induced by commercial fisheries. Ibis 139:631-637.

Oro, D., R. Torres, C. Rodríguez, and H. Drummond. 2010. Climatic influence on demographic parameters of a tropical seabird varies with age and sex. Ecology 91:1205-1214.

Orzack, S. H., U. K. Steiner, S. Tuljapurkar, and P. Thompson. 2011. Static and dynamic expression of life history traits in the northern fulmar Fulmarus glacialis. Oikos 120:369-380.

Pardo, D., C. Barbraud, M. Authier, and H. Weimerskirch. 2013. Evidence for an age-dependent influence of environmental variations on a long-lived seabird's life-history traits. Ecology 94:208-220.

Péron, G., P.-A. Crochet, R. Choquet, R. Pradel, J.-D. Lebreton, and O. Gimenez. 2010. Capture-recapture models with heterogeneity to study survival senescence in the wild. Oikos 119:524-532.

Pinheiro, J., D. Bates, S. DebRoy, and D. Sarkar. 2013. nlme: linear and nonlinear mixed effects models. R Package, version 3.1-89. http://cran.r-project.org/

Proaktor, G., E. J. Milner-Gulland, and T. Coulson. 2007. Agerelated shapes of the cost of reproduction in vertebrates. Biology Letters 3:674-677.

Pyle, P., W. J. Sydeman, and M. Hester. 2001. Effects of age, breeding experience, mate fidelity and site fidelity on breeding performance in a declining population of Cassin's auklets. Journal of Animal Ecology 70:1088-1097.
Ratcliffe, N., R. W. Furness, and K. C. Hamer. 1998. The interactive effects of age and food supply on the breeding ecology of great skuas. Journal of Animal Ecology 67:853862.

Rebke, M., T. Coulson, P. H. Becker, and J. W. Vaupel. 2010. Reproductive improvement and senescence in a long-lived bird. Proceedings of the National Academy of Sciences USA 107:7841-7846.

Reed, T. E., L. E. B. Kruuk, S. Wanless, M. Frederiksen, E. J. A. Cunningham, and M. P. Harris. 2008. Reproductive senescence in a long-lived seabird: rates of decline in late-life performance are associated with varying costs of early reproduction. American Naturalist 171:E89-E101.

Reid, J. M., E. M. Bignal, S. Bignal, D. I. McCracken, and P. Monaghan. 2003. Age-specific reproductive performance in red-billed choughs Pyrrhocorax: patterns and processes in a natural population. Journal of Animal Ecology 72:765-776.

Sanz-Aguilar, A., G. Tavecchia, R. Pradel, E. Mínguez, and D. Oro. 2008. The cost of reproduction and experiencedependent vital rates in a small petrel. Ecology 89:3195-3203.

Stearns, S. C. 1976. Life-history tactics: A review of the ideas. Quarterly Review of Biology 51:3-47.

Stearns, S. C. 2000. Life history evolution: successes, limitations, and prospects. Naturwissenschaften 87:476-486.

Stearns, S. C., and T. J. Kawecki. 1994. Fitness sensitivity and the canalization of life-history traits. Evolution 48:1438-1450.

Sydeman, W. J., J. F. Penniman, T. M. Penniman, P. Pyle, and D. G. Ainley. 1991. Breeding performance in the western gull: effects of parental age, timing of breeding and year in relation to food availability. Journal of Animal Ecology 60: 135-149.

Tavecchia, G., R. Pradel, M. Genovart, and D. Oro. 2007. Density-dependent parameters and demographic equilibrium in open populations. Oikos 116:1481-1492.

Trumbo, S. T. 2009. Age-related reproductive performance in the parental burying beetle, Nicrophorus orbicollis. Behavioral Ecology 20:951-956.

Velando, A., H. Drummond, and R. Torres. 2006. Senescent birds redouble reproductive effort when ill: confirmation of the terminal investment hypothesis. Proceedings of the Royal Society B 273:1443-1448.

Vieyra, L., E. Velarde, and E. Ezcurra. 2009. Effects of parental age and food availability on the reproductive success of Heermann's Gulls in the Gulf of California. Ecology 90: 1084-1094.

Violle, C., B. J. Enquist, B. J. McGill, L. Jiang, C. H. Albert, C. Hulshof, V. Jung, and J. Messier. 2012. The return of the variance: intraspecific variability in community ecology. Trends in Ecology and Evolution 27:244-252.

Weimerskirch, H. 1990. The influence of age and experience on breeding performance of the Antarctic Fulmar (Fulmarus glacialoides). Journal of Animal Ecology 59:867-875.

Weladji, R. B., J.-M. Gaillard, N. G. Yoccoz, Ø. Holand, A. Mysterud, A. Loison, M. Nieminen, and N. C. Stenseth. 2006. Good reindeer mothers live longer and become better in raising offspring. Proceedings of the Royal Society B 273: $1239-1244$.

Zuur, A. F., E. N. Ieno, N. Walker, A. A. Saveliev, and G. M. Smith. 2009. Mixed effects models and extensions in ecology with R. Springer, New York, New York, USA.

\section{Supplemental Material}

\section{Appendix}

A list of papers testing the effects of age, together with environmental drivers and a table with all models tested for laying dates and egg volume (Ecological Archives E095-039-A1). 